\title{
COMPOSIÇÃO EM ÁCIDOS GRAXOS DO ÓLEO DA POLPA DE AÇAÍ EXTRAÍDO COM ENZIMAS E COM HEXANO ${ }^{1}$
}

\author{
RHUTYNÉIA JOANA SILVADONASCIMENTO², SONIACOURI ${ }^{3}$, \\ ROSEMAR ANTONIASSI ${ }^{4}$, SUELY PEREIRẢ FREITAS ${ }^{5}$
}

RESUMO-A palmeira Euterpe oleracea (Mart.), conhecida como açaizeiro, é nativa da Amazônia e tem-se destacado pelo potencial dos seus produtos, em especial pela importância econômica para a fruticultura regional. A polpa de açaí contém alto teor de óleo vegetal, cerca de 53\% em base seca, e é uma fonte de ácidos graxos essenciais. Neste trabalho, a composição em ácidos graxos da fração lipídica da polpa de açaí foi determinada por cromatografia gasosa de alta resolução. O óleo foi obtido pelo processo enzimático ou por extração com n-hexano. A extração enzimática, em meio aquoso, tem sido indicada como uma alternativa para a obtenção de óleos vegetais derivados de polpas de frutas. Os resultados apresentaram diferenças não significativas na composição em ácidos graxos dos óleos provenientes das diferentes técnicas de extração. Em ambos os casos, houve predominância dos ácidos graxos monoinsaturados $(68 \%$ a $71 \%)$ e de ácidos graxos poliinsaturados $(7,7 \%$ a $10,6 \%)$.

Termos para Indexação: óleo de açaí, ácidos graxos, tecnologia enzimática.

\section{FATTY ACIDS COMPOSITION OF AÇAÍ PULP OIL OBTAINED BY ENZYMATIC TECHNOLOGY AND HEXANE}

ABSTRACT-Açaí (Euterpe oleracea Martius) is a typical palm tree from the Amazon, growing spontaneously in states of Pará, Amazonas, Amapá and Maranhão. It has been highlighted by the potential of its products, especially because of the economic importance for the regional fruit growing. The açaí fruits are very appreciated by their pulp flavour. In the açaí pulp, there is a significant amount of lipids, around $53 \%$, in a dry basis, turning out to be an excellent source of essential fatty acids. The main purpose of the present work was to establish the fatty acid content in the lipid fraction of açaí pulp using high resolution gaseous chromatography. The açaí oil was obtained by enzymatic technology in water has been indicated as an alternative for vegetable oils extraction from pulp of fruits. A significant difference was not observed in the composition of the fatty acids present in açaí oil obtained from either process. In both cases, the oil is high in monounsaturated fatty acids (68\% to $71 \%)$ and in polyunsaturated fatty acids $(7.8 \%$ to $10.6 \%)$.

Index Terms: açaí oil, fatty acids, enzymatic technology.

\section{INTRODUÇÃO}

A região amazônica apresenta grande quantidade de plantas perenes, com particular relevância para as espécies frutíferas. Dentre essas frutas, destaca-se o açaí. O açaí, fruto do açaizeiro (Euterpe oleracea Martius), é importante para o desenvolvimento agroindustrial da região amazônica. A produção de açaí, na microrregião de Belém, ocorre em todos os meses do ano, porém concentra-se no segundo semestre, principalmente entre os meses de setembro e dezembro. Esse fruto contém lipídios, proteínas, fibras e antocianinas. Seu consumo na região Norte do Brasil se faz, em geral, combinado com outros alimentos regionais ou, ainda, na forma de sorvetes, cremes, mingaus, geléias e licores. No Sudeste, o açaí é consumido de forma distinta da praticada na região Norte, pois o objetivo dos consumidores é a ingestão de um alimento energético e nutricionalmente completo. Para essa finalidade são adicionados ao açaí cereais, frutas e carboidratos de assimilação rápida para compensar sua deficiência em açúcares simples (Oliveira, 1995; Nogueira, 1995).

Segundo Rogez (2000), o óleo de açaí, da mesma forma que o óleo de oliva e abacate, é rico em ácidos graxos monoinsaturados e poliinsaturados, respectivamente, 60 e $14 \%$ (Tabela 1). Os óleos de oliva e abacate, por suas características químicas relacionadas com a respectiva composição em matéria insaponificável, são utilizados tanto para consumo in natura quanto na indústria de cosméticos. Esses produtos conquistaram uma fatia nobre do mercado e são, em geral, comercializados com um valor superior ao dos demais óleos vegetais. Diferentemente do óleo de abacate, que já foi avaliado para diferentes variedades

${ }^{1}$ (Trabalho 139-07).Recebido em: 31-05-2007. Aceito para publicação em: 21-09-2007.

${ }^{2}$ M.Sc. Instituto de Tecnologia-UFRRJ, BR-465, Km 7, Seropédica, Rio de Janeiro - CEP. 23.890-000. e-mail: rhutyneia@yahoo.com.br.

${ }^{3}$ D.Sc. Embrapa Agroindústria de Alimentos- Av. das Américas, 29501-Guaratiba' CEP: 23020-470, Rio de Janeiro- Brasil. Tel. 552124109618 , fax: 55 21 24109529; e-mail: scoury@ctaa.embrapa.br.

${ }^{4}$ D.Sc. Embrapa Agroindústria de Alimentos- Av. das Américas, 29501-Guaratiba CEP: 23020-470, Rio de Janeiro- Brasil. Tel. 552124109618 , fax: 55 21 24109529; e-mail: rosemar@ctaa.embrapa.br.

${ }_{5}^{5}$ D.Sc. UFRJ/Escola de Química/DEQ; Ilha do Fundão, Centro de Tecnologia, Bloco E, sala 207. CEP: 21949-900, Rio de Janeiro - Brasil. Tel. 55 21 25627634, e-mail: freitasp@eq.ufrj.br. 
cultivadas no Brasil (Szpiz et al., 1987; Freitas et al., 1993; Antoniassi, 1998), a caracterização do óleo de açaí carece de mais estudos. Dados contraditórios relativos à sua composição em ácidos graxos ainda são encontrados na literatura.

A extração enzimática consiste no uso de enzimas que hidrolisam a parede celular dos vegetais liberando o óleo para o meio aquoso. O óleo é separado da água por centrifugação, resultando em um produto praticamente isento de fosfatídeos e, conseqüentemente, com baixa turbidez (Freitas et al., 1998; Couri \& Freitas, 2001; Nascimento, 2004). Essa tecnologia desponta como uma alternativa potencial para extração de óleos vegetais, uma vez que o uso de solventes derivados de petróleo deverá ser substituído, no futuro, por processos tecnológicos mais sustentáveis, para atender às exigências dos órgãos governamentais de proteção ao meio ambiente (Parmentier, 2004). Devido ao elevado custo das enzimas comerciais, a implantação industrial desse processo está limitada, até o momento, à obtenção de azeite de oliva (Christensen, 1991; Da-Silva et al., 1997).

Neste trabalho, a técnica de cromatografia gasosa de alta resolução foi aplicada para identificar e quantificar os ácidos graxos do óleo da polpa de açaí obtido, aplicando-se o processo enzimático e o tradicional.

\section{MATERIAL E MÉTODOS}

\section{Matéria-prima}

Foram utilizadas amostras da polpa fresca de açaí comercial, com teor de sólidos totais entre 11\% e 14\% (açaí médio). A polpa foi cedida pela cooperativa Palamaz, situada em BelémPA. O lote da polpa foi homogeneizado em um liquidificador industrial e acondicionado em embalagens plásticas individuais de $500 \mathrm{~g}$, vedadas e congeladas.

A polpa de açaí foi analisada quanto ao teor de sólidos totais, extrato etéreo, acidez total, umidade, cinzas e proteína, de acordo com métodos-padrão da AOAC (2000).

\section{Extratos enzimáticos}

Foram utilizados dois tipos de extratos enzimáticos, um comercial, da Novo Nordisk, e outro, produzido em escala de bancada por fermentação semi-sólida (Couri \& Farias,1995; Couri \& Freitas, 2001). Os extratos foram caracterizados quanto às atividades das enzimas poligalacturonase (EC 3.2.1.15), celulases FPCase (EC 3.2.1.91) e CMCase (EC 3.2.1.4), xilanase (EC 3.2.1.8), respectivamente, conforme Couri (1993), Wood \& GarciaCampayo (1990), Ristroph \& Humphrey (1985) e Nery (1996).Os grupos redutores, produtos das reações enzimáticas, foram medidos pelo método de Somogyi et al. (1952).

\section{Extração enzimática}

A extração enzimática em meio aquoso do óleo de açaí seguiu o procedimento recomendado por Freitas et al., (1993). Amostras de $100 \mathrm{~g}$ de polpa de açaí foram submetidas à prétratamento térmico durante 15 minutos a $85^{\circ} \mathrm{C}$, para inativação das enzimas naturais presentes no fruto. Após resfriamento das amostras, os extratos enzimáticos foram adicionados separadamente à polpa de açaí, na proporção de $0,3 \%$ em relação ao peso da polpa. A seguir, as amostras foram incubadas a $45^{\circ} \mathrm{C}$, em banho termostático, a $65 \mathrm{rpm}$, por 90 minutos. Para inativação das enzimas, as amostras foram aquecidas em banho-maria a $80^{\circ} \mathrm{C}$ e mantidas nesta temperatura por 15 minutos. As misturas foram centrifugadas por $30 \mathrm{~min}$ a $3.500 \mathrm{rpm}$. Para quantificação analítica do óleo extraído, éter de petróleo foi adicionado aos tubos de centrífuga cujos sobrenadantes foram transferidos para um funil de separação. A fase aquosa foi desprezada, e a fase contendo o óleo foi filtrada em papel contendo sulfato de sódio anidro para remoção da umidade residual. $\mathrm{O}$ solvente foi recuperado em evaporador rotatório, sob pressão reduzida a $50^{\circ} \mathrm{C}$, e, em seguida, o óleo foi mantido em uma estufa a $50^{\circ} \mathrm{C}$ até peso constante. $\mathrm{O}$ produto final foi quantificado pelo método gravimétrico e conservado em vidro âmbar sob refrigeração.

\section{Extração com éter de petróleo.}

A hidrólise ácida foi o método utilizado para extrair o óleo da polpa in natura e da torta resultante da extração aquosa. Para isso, foram utilizados éter de petróleo e éter etílico, de acordo com o método 922.06 - 32.1.14.F da AOAC (2000).

\section{Determinação dos ácidos graxos}

As diferentes frações de óleo foram analisadas sob a forma de ésteres metílicos, preparados de acordo com o método proposto por Hartman \& Lago (1973), em cromatógrafo gasoso de alta resolução (HP 5890), munido de detector por ionização de chama $(F I D)$ e coluna de sílica fundida de cianopropil siloxano $(60 \mathrm{mx} 0,2 \mathrm{mmx} 0,32 \mathrm{~mm})$. A temperatura inicial da coluna foi de $150^{\circ} \mathrm{C}$, e a temperatura final, de $200^{\circ} \mathrm{C}$, com programação de $1,3^{\circ} \mathrm{C}$ /minuto; as temperaturas do injetor e do detector foram $250^{\circ} \mathrm{C}$ e $280^{\circ} \mathrm{C}$, respectivamente, e o fluxo de hidrogênio foi de $2,5 \mathrm{~mL} /$ minuto. Os ésteres foram identificados por comparação dos tempos de retenção frente a padrões (NU CHEK Inc. Elysian, IL), e a quantificação, por normalização interna.

\section{RESULTADOS E DISCUSSÃO}

As principais características químicas e físicas da polpa de açaí utilizada estão apresentadas na Tabela 2. A polpa, ligeiramente ácida, contém alto teor de umidade e baixo teor de sólidos solúveis. A fração lipídica representou $42,61 \%$ do peso total, em base seca. Esse resultado é inferior aos valores reportados por Alexandre et al. (2004) e Belitz \& Groch (1992) (citado em Rogez, 2000), que encontraram, em média, 52,64\% e $48,24 \%$, respectivamente. Essas diferenças são consideradas naturais, quando a matéria -prima é de origem vegetal e decorrem da variedade da planta, da época da colheita dos frutos, do processamento industrial e/ou das condições de condicionamento e armazenamento, visando à sua conservação.

$\mathrm{O}$ extrato preparado apresentou valores de atividade enzimática inferiores à do extrato comercial (Tabela 3); entretanto, em relação ao rendimento médio de extração do óleo da polpa de açaí, os resultados foram equivalentes. Freitas et al., (1993) observaram esse mesmo comportamento na extração do óleo da polpa de abacate.

O óleo obtido pelo processamento da polpa com o extrato 
enzimático preparado apresentou cerca de $71 \%$ de ácidos graxos insaturados, $60,81 \%$ de monoinsaturados e $10,36 \%$ de poliinsaturados, enquanto o óleo extraído com solvente orgânico, cerca de $68 \%$ de ácidos graxos insaturados, 60,33\% de monoinsaturados e $7,83 \%$ de poliinsaturados. Neste caso $3,54 \%$ dos ácidos graxos não foram identificados (Tabela 4).

O conteúdo de ácidos graxos, encontrado no óleo extraído a partir da torta resultante da extração enzimática, apresentou cerca de $70 \%$ de insaturados, $60 \%$ de monoinsaturados e $9,68 \%$ de poliinsaturados, e foi o único a apresentar traços de ácidos graxos trans, cerca de $0,09 \%$ (Tabela 4 ).

Tabela 4: Composição, em ácidos graxos, do óleo de açaí extraído, com enzimas e com solvente, da polpa e da torta resultante da extração enzimática.

O óleo de açaí apresentou elevado teor de ácidos graxos insaturados, 68 a $71 \%$, o que coloca esse fruto em uma condição atraente para o mercado de alimentos funcionais. $\mathrm{O}$ uso de matérias-primas ricas em ácidos graxos monoinsaturados e poliinsaturados é de grande interesse para as indústrias de alimentos e bebidas que buscam alternativas para elaboração de produtos mais saudáveis (Hornstra, 1999).

Dos sete ácidos graxos do óleo de açaí citados por Rogez (2000), quatro deles, C18:0 esteárico, C18:1 (cis 9) oléico, C18:2 linoléico e o C20:0 araquídico, foram quantificados ligeiramente abaixo dos valores reportados por esse autor. O teor de ácidos graxos poliinsaturados foi inferior a $11 \%$. Esse resultado é considerado bom, do ponto de vista da estabilidade do óleo, uma vez que esses ácidos graxos, devido a sua quantidade de duplas ligações, favorecem a oxidação dos lipídios (Antoniassi, 2001). Acredita-se que os componentes não-identificados nas três amostras analisadas do óleo de açaí sejam, provavelmente, substâncias não-lipídicas arrastadas durante o processo de extração ou produtos resultantes de degradação térmica. Observou-se que o óleo extraído com solvente removeu maior quantidade de compostos não-identificados $(3,54 \%)$, o que indica a necessidade de refino.

O óleo extraído com solvente apresentou teor de ácidos graxos poliinsaturados $2,5 \%$ menor que o valor encontrado no óleo extraído com enzimas (Tabela 4). No caso dos ácidos graxos saturados, foi observada uma diferença inferior a $1 \%$. Estes valores não foram significativos quando se considera um desviopadrão de $\pm 5 \%$ associado aos resultados obtidos por cromatografia gasosa.
TABELA 1- Composição em ácidos graxos dos óleos de oliva, açaí e abacate.

\begin{tabular}{lccc}
\hline \multicolumn{1}{c}{ Ácidos graxos $(\%)$} & Óleo de oliva* & Óleo de açá;** & Óleo de abacate*** \\
\hline C 16:0 Palmítico & $7,5-20$ & 22,0 & 28,1 \\
C16:1 Palmitolelico & $0,3-3,5$ & 2,0 & 9,1 \\
C18:0 Esteárico & $0,5-5,0$ & 2,0 & 0,8 \\
C18:1 Oléico & $55-83$ & 60,0 & 45,7 \\
C18:2 Linoléico & $3,5-21$ & 12,0 & 15,4 \\
C18:3 Linolênico & 0,9 & Trą̧os & 0,8 \\
C20:0 Araquíidico & 0,6 & 2,5 & nd \\
\hline
\end{tabular}

nd- Não-detectado. Fontes: * BRASIL (1999), **Rogez (2000), ***FREITAS et al. (1993);

TABELA 2- Características físicas e químicas da polpa de açaí.

\begin{tabular}{cc}
\hline Análises & Polpa de açaí.(g/100g) \\
\hline Umidade & 89,18 \\
Lipídios & 4,61 \\
Proteínas & 0,17 \\
Cinzas & 0,41 \\
Carboidratos (por diferença) & 5,63 \\
Acidez em ácido cítrico & 0,19 \\
\hline pH & 5,0 \\
Sólidos Solúveis Totais & $2,7^{\circ}$ Brix
\end{tabular}

TABELA 3- Atividades enzimáticas do extrato comercial e do extrato preparado.

\begin{tabular}{lcc}
\hline \multicolumn{1}{c}{ Enzimas } & Pectinex $(\mathrm{U} / \mathrm{mL})$ & CTAA $(\mathrm{U} / \mathrm{mL})$ \\
\hline Poligalacturonase & 279,64 & 53,64 \\
Celulase cristalina & 1,26 & 0 \\
Carboximetilcelulase & 27,15 & 0,39 \\
Xilanase & 158,48 & 0 \\
\hline
\end{tabular}

TABELA 4 - Composição em ácidos graxos do óleo de açaí extraído, com enzimas e com solvente, da polpa e da torta resultante da extração enzimática.

\begin{tabular}{lccc}
\hline & Enzimático a partiri da polpa & Solvente a partir da polpa & Solvente a partir da torta \\
\hline C12:0 Láurico & 0,04 & 0,07 & 0,08 \\
C14:0 Mirístico & 0,11 & 0,13 & 0,14 \\
C16:0 Palmítico & 25,93 & 26,18 & 26,78 \\
C16:1 Palmitoleico & 4,88 & 4,88 & 4,99 \\
C18:0 Estérico & 1,86 & 1,81 & 1,74 \\
C18:1 (trans) Eládico & $*$ & $*$ & 0,09 \\
C18:1 (cis 9) Oleico & 52,54 & 52,00 & 51,46 \\
C18:1 (cis 11) Vacênico & 3,39 & 3,45 & 3,46 \\
C18:2 Linoléico & 9,72 & 7,28 & 8,87 \\
C18:3 Linolênico & 0,64 & 0,55 & 0,81 \\
C20:0 Araquídico & 0,12 & 0,11 & 0,10 \\
Não identificados & 0,77 & 3,54 & 1,43 \\
Total saturados & 28.06 & 28.3 & 28.84 \\
Total insaturados & 71.17 & 68.16 & 69.68 \\
\hline * Ausente & & &
\end{tabular}




\section{CONCLUSÃO}

O perfil em ácidos graxos do óleo de açaí qualifica-o como um óleo comestível especial, pois apresenta, predominantemente em sua composição, ácidos graxos monoinsaturados (de até $61 \%$ ) e ácidos graxos poliinsaturados (de até 10,6\%), ambos recomendados para prevenção de doenças cardiovasculares. A composição em ácidos graxos dos óleos obtidos pelo processo enzimático em meio aquoso não difere de forma significativa dos resultados obtidos para o óleo extraído com solvente. O extrato enzimático preparado foi equivalente ao comercial com relação ao rendimento de extração do óleo.

\section{AGRADECIMENTOS}

À CAPES, CNPq e FAPERJ, pelo apoio financeiro.

\section{REFERÊNCIAS}

ALEXANDRE, D.; CUNHA, R.L.; HUBINGER, M.D. Conservação do açaí pela tecnologia de obstáculos. Ciência e Tecnologia de Alimentos, Campinas, v. 24, n. 1, p. 114-119, 2004.

ANTONIASSI, R.; PECANHA, B.R. B; LAGO, R.C.A. Efeito da adição de óleo de abacate na estabilidade oxidativa de óleos de soja e girassol. In: CONGRESSO BRASILEIRO DE CIÊNCIA E TECNOLOGIADEALIMENTOS, 16., 1998, Rio de Janeiro. Anais... Campinas-SP, UNICAMP, 1998.

ANTONIASSI, R. Métodos de avaliação de estabilidade oxidativa de óleos e gorduras. Boletim do Centro de Pesquisa e Processamento de Alimentos, Curitiba, v. 19, n. 2, p. 353-380, 2001.

AOAC. International official methods of analyses. $17^{\text {th }} \mathrm{ed}$. Washington D.C., 2000.

BRASIL. Resolução-RDC no 482. Regulamento técnico para fixação de identidade e qualidade de óleos e gorduras vegetais. Diário Oficial da União. Poder Executivo, Brasília, DF, 13 out. 1979.

CHRISTENSEN, F.M. Extraction by aqueous enzimatic process. International News on Fat, Oils and related Materials, Illinois, v. 2, n. 11, p. 984-987, 1991.

COURI, S. Efeito de cátions na morfologia do agregado e na produção de poligalacturonase por Aspergillus niger mutante 3T5B8. 1993. Tese (Doutorado Processos químicos e bioquímicos)- Escola de Química, Universidade Federal do Rio de Janeiro, Rio de Janeiro, 1993.
COURI, S.; FARIAS, S.P. Genetic manipulation of Aspergillus niger for increased synthesis of pectinolitic enzymes. Revista de Microbiologia, São Paulo, v. 26, n. 4, p.314-317, 1995.

COURI, S.; FREITAS, S.P. Aplicação de enzimas na extração aquosa de óleos vegetais. In: MERCADANTE, A. Z; BOBBIO, F. O; BOBBIO, P. A; PEREIRA, J. L; PASTORE, G. M. (Org.). Ciências de Alimentos: avanços e perspectivas. Campinas: UNICAMP, 2001.v.2, p. 28-32.

DA-SILVA; R.; FRANCO,R.; CÉLIA, M.L.; GOMES, E. Pectinases, hemicelulases e celulases, ação, produção e aplicação no processamento de alimentos. Boletim da SBCTA, Campinas, v.31, n.2, p. 249-260, 1997.

FREITAS, S. P.; LAGO, R.C.A.; QASSIM, R.Y. Economics analysis of enzymatic extraction of avocado oil, Rivista Italiana delle Sostanze Grasse, Milano, v.75, p.15-19, 1998.

FREITAS, S.P.; LAGO, R.C.A.; JABLONKA, F.H.; HARTMAN, L. Extraction aqueuse enzimatique de l'huile d'avocat a partir de la pulpe fraîche. Revue Française des Corps Gras, Paris, v.41, p. 365-371, 1993.

HARTMAN, L.; LAGO, R.C.A. Rapid preparation of fatty acid methyl esters from lipids. Laboratory Practice, Londres, v. 22, p. 475-477, 1973.

HORNSTRA, G. Lipids in functional foods in relation to cardiovascular disease. Fett/Lipid, Berlin, v. 101, n. 12, p. 456466, 1999.

NASCIMENTO, R.J.S. Extração aquosa enzimática do óleo de açaí. 2004. 58 f. Dissertação (Mestrado em Ciência e Tecnologia de Alimentos) - Departamento Tecnologia de Alimentos, Universidade Federal Rural do Rio de Janeiro, Rio de Janeiro, 2004.

NERY, I.A. Acompanhamento cinético da linhagem mutante Aspergillus niger 3T5B8 em fermentação semi-sólida. 1996. Dissertação (Mestrado Curso em Ciência e Tecnologia de Alimentos) - Departamento de Tecnologia de Alimentos/Instituto de Tecnologia, Universidade Federal Rural do Rio de Janeiro, Rio de Janeiro, 1996.

NOGUEIRA, O.L; CARVALHO, C.; MULLER, C.; GALVÃO, E.; SILVA, H.; RODRIGUES, J.; OLIVEIRA, M.; CARVALHO NETO, J.O.; NASCIMENTO, W.; CALVAZARRA, B. A Cultura do açaí. Brasília: Embrapa/Centro de Pesquisa Agroflorestal da Amazônia Oriental, 1995. 50p. (Coleção plantar, 26).

OLIVEIRA, M. do S.P. Avaliação do modo de reprodução e de caracteres quantitativos em 20 acessos de açaizeiro (Euterpe oleracea Mart. Arecaceae) em Belém-Pa. Recife-Pe, Brasil. 1995. 146 f. Dissertação (Mestrado em Botânica) -Universidade Federal de Pernambuco, Recife, 1995. 
PARMENTIER, M.; GUILLEMIN, S.; BARBAR, R.; LINDER, M. FANNI, J. De nouveaux procédés d'extraction des huiles pour des produits finis de haute qualité. Oleagineux Corps Lipids, Edinbourg, v. 11, n. 6, p. 377-380, 2004.

RISTROPH, D.L; HUMPHREY, A.E. Kinetic characterization of the extracellular xylanases of Thermonospora sp. Biotechnology and Bioengineering, New York, v.27, p. 832-836, 1985.

ROGEZ, H. Açaí: preparo, composição e melhoramento da conservação. Belém: Universidade Federal do Pará, 2000.
SOMOGYI, M. Notes on sugar determination. Journal of Biological Chemistry, Baltimore, v. 193, p. 267-272, 1952.

SZPIZ, R.R; JABLONKA, F.H.; PEREIRA, D.A. Avaliação do óleo de cultivares de abacate provenientes da região do cerrado. Rio de Janeiro: EMBRAPA-CTAA, 1987. (Boletim de Pesquisa, 16)

WOOD, T.M.; GARCIA-CAMPAYO, V. Enzimology of cellulose degradation. Biodegradation, Dordrecth, v. 1, p.147-161, 1990. 